\title{
MAKING MUSIC, MAKING MONEY: INFORMAL MUSICAL PRODUCTION AND PERFORMANCE IN VENDA, SOUTH AFRICA
}

\author{
Fraser G. McNeill
}

\section{INTRODUCTION:}

\section{FORMAL AND INFORMAL MUSICAL PRODUCTION IN SOUTH AFRICA}

South Africa's popular music scene has been the subject of academic scrutiny for several decades. Charting the growth of the urban entertainment industry (Coplan 1985; Erlman 1991, 1996), up to present day recording processes in state-of-the-art studios (Meintjes 2003), this broad body of work reflects the politics and pragmatics of production and performance from apartheid to the present day. ${ }^{1}$ Much of this recent work has focussed on kwaito, which was until recently the dominant urban musical form in contemporary South Africa (Steingo 2005; Baines 2006). This paper offers an ethnographic analysis of the informal production of reggae: a genre and a recording process which have hitherto been neglected in this literature. By focussing on the economic dimensions of the informal music industry, the current study takes as its focus the ways in which musicians' need to make a living dovetails with government funding policy, resulting - possibly inadvertently - in a culture of self-censorship which betrays the 'creative freedoms' allegedly enjoyed by performing artists in the post apartheid-era (Coplan 2005: 9). In seeking to convert their cultural capital into a cut of cash from a government tender, musicians sacrifice their artistic freedom and integrity in a process which could be thought of as 'tendersized performance'.

The distinction between formal and informal musical production is key to this argument. A handful of well established national and international record labels - such as Gallo/Warner and $\mathrm{EMI} / \mathrm{CCP}$ - and a host of smaller music companies, maintain a lively and diverse formal music scene based mostly in the urban centres and townships, stretching to and from the rural hinterlands. Musical tastes are catered for across class and cultural divides, and music shop categories reflect the broad diversity of popular genres; from Afrikaans folk to deep house. Prominent gospel, kwaito and 
house artists display conspicuous patterns of consumption, leading lavish lifestyles and embracing the 'bling culture' which has become synonymous with a recently enriched upwardly mobile class of politically connected 'tenderpreneurs'. Purveyors of other musical styles such as 'traditional', 'world', and 'folk' have also become well established through their association with major labels. Heavy metal and hip-hop is sung in Afrikaans and produced by record companies to meet the demands of South Africans at home and abroad. South African Jazz, Afro-beat and African Rumba fills the shelves in music shops throughout Europe and North America, and there is a steady flow of international artists participating in South Africa's various and vibrant live music circuits. Whilst much of the music recorded in South Africa is routinely pirated and shared illegally through the internet, there is good money to be made in making music with the big labels. Record companies recoup their costs for production and marketing by taking a significant share from CD sales. Musicians make the bulk of their money from once-off up-front album 'incentives' and ticket sales from live performances, which conventionally go to the artist. Such performances, at least in theory, promote the sale of records and other merchandise, from which the label makes more profit, and funds more recordings.

Running parallel to the well established music companies, South Africa is host to an abundance of informal recording studios. Whilst there are clear connections between these and the more formal processes of musical production - and various sectors where the boundaries between the two are blurred - the informal economy of popular music has several distinguishing features. Central to its continued survival is the abundance of cheap second-hand computers and pirated software. Illegal copies of computer programmes such as Nwendo and Cue-Base are easily available, and once installed they provide a virtual recording studio which, with practice, talent and a reasonable microphone, can produce recordings that closely mimic a professional sound. The informal scene is also distinguished by the ways in which money and debt circulate between musicians, producers and sponsors in patron/client type scenarios. Musicians are not awarded 
'deals' from a record label and formal contracts are rare. Mutual trust between the parties involved is vital in maintaining the industry, and reputations are tarnished when obligations are left unfulfilled. Musicians pay a producer directly - often through the assistance of a sponsor - and the quality of their final recording reflects the resources available for the cash they have to offer. Composers often strike a deal with a producer in which small amounts of cash are paid - often on a song by song basis - until an album is complete. However, an album achieves airplay - and thus a producer receives publicity - only once it is released. The pressure to release often results in albums being completed before the producer has been paid. Cycles of debt are accrued, and if cash is not forthcoming then a musician may settle his bill by helping the producer on a different project; for example as a session musician or on backing vocals for another artist. A final main point of distinction between formal and informal recording studios is that the latter are rarely registered as businesses with the South African Revenue Service: They pay no tax. This reflects the small profits accumulated in the industry and the reliance on cycles of trust/debt, and suggests a distance from state scrutiny by operating 'under the radar'. This distance, I argue, is illusionary.

The sum of these informal musical structures can be thought of as a 'second economy'. But it does not follow that they are disconnected from the 'first economy' of formal musical production. On the contrary, whilst the two may be structurally distinct, the ultimate goal for most artists in the second economy is to cross over into the relative security of a record deal, although very few succeed in this aim. This is, of course, a pattern that is replicated globally. The informal music scene supports - and is supported by - unsigned artists, and brings them to the attention of the big labels. In some parts of the world this has created underground scenes where signing to a label is seen as 'selling out', such as the punk-rock music that became popular in New York and the UK in the early 1970s. There is nothing distinctly South African, then, about the distinction between formal and less formal modes of musical production. But what makes the South African case distinctive, and interesting in the post apartheid-era, is the role of the state in regulating live 
performance, and thus to some extent studio recordings, through the allocation of funding for entertainment at government shows.

Without the financial backing of a record company behind them, musicians in the South African informal sector are forced to seek alternative means to make money from making music. Various activities are undertaken in this regard, and artists can often be found selling CDs from their cars, or in miming shows, known as 'promotions', in and around shopping complexes and beer halls (cf. Lamont 2010 in Kenya). The big money, however, is not in local promotions, for which musicians often have to rent public space, and can subsequently make a loss, more of which below. More substantial financial reward can be found through participation in shows organised by the provincial or local government to celebrate South Africa's numerous public holidays, and on other occasions throughout the year. The organization of these performances is either arranged directly through government departments or, more commonly, put out to tender. I argue in this paper that the space between the potential creative freedom of the informal sector and state regulation of musical autonomy is bridged by the financial necessity to engage with, and perform for, the 'tenderpreneurs' who hire and fire musicians for government shows.

\section{FROM RICHES TO RAGS: A BRIEF HISTORY OF A VENDA MUSICIAN}

For almost thirty years, the Venda reggae scene has been dominated by one man: Colbert Mukwevho. $^{2}$ Born in 1965, and with eighteen albums to his name (in 2010), Colbert's career has endured highs and lows, traversing a path over the years from the formal to the informal music sector. His is not a tale of rags to riches, but one of remarkable fortitude in an industry known for its ruthlessness pursuit of younger talent. As a child in the early 1970s, Colbert performed with his father's band, The Thrilling Artists, playing a style that mixed township jive with Venda/Shangaan melodies (see McNeill Forthcoming). He progressed from playing bass and singing backing vocals 
to become the lead singer before the age of ten. His energetic performances and high pitched and accurate melodies attracted crowds to their shows, and before long The Thrilling Artists landed a recording deal with the recently formed Radio Venda, the public broadcaster for the former homeland, with whom they recorded three albums. They were well paid for the recordings, with cash up front, for which they relinquished all copyright and subsequent control over their material.

In his early teens, Colbert was deeply influenced by the provocative recordings of Bob Marley, Peter Tosh, and other reggae artists who received airplay on Radio Freedom. ${ }^{3}$ Reggae music was treated with suspicion by the intelligence forces in the former homeland, and it existed on the fringes of legality. Whilst not explicitly illegal, anyone caught listening to banned songs could expect to be interrogated at one of the infamous 'questioning centres', and to have their activities closely monitored. State broadcasters during apartheid did play reggae, but their repertoire was limited to songs deemed to be 'safe', with no political content (see Drewtt and Cloonen 2006). Love songs such as Peter Tosh's Ketchy Shuby and Jimmy Cliff's Love Solution were aired, whilst songs such as Legalize it, and The Power and the Glory - by the same artists and on the same albums were banned. But this did not stop people listening to them. As Colbert recalled:

We had a friend - the son of a chief - who travelled out of Venda a lot and came back with these [reggae] albums. We would meet at night and listen to them... it changed the way we thought about music. (Interview with Colbert Mukwevho November $\left.12^{\text {th }} 2009\right)$.

The lyrics, which often promoted pan-African ideology, spoke directly to the South African black population. In 1977, when Colbert Mukwevho was twelve and already the lead singer of the Thrilling Artists, Peter Tosh released his Equal Rights album, with the track 'Apartheid', a stinging attack on the Nationalist government and an explicit call to arms against it. In 1979, Bob Marley 
released Survival, widely regarded as his most militant and political album in which he dedicated several songs to the fight against racial segregation in South Africa. Despite attempts to prevent people from listening to reggae, then, it became hugely popular. Lyrics from reggae songs were incorporated into struggle songs, and growing dreadlocks became a physical marker of resistance.

In the mid 1980s, Colbert Mukwevho split from The Thrilling Artists to form his own band. He began to imitate the 'one-drop' reggae rhythm - with emphasis on the off beat - and the distinctive 'chicken-scratch' guitar style which he lifted directly from Peter Tosh. Set against this early reggae / rock steady sound, Colbert wrote songs in Tshivenda that were suitable for airplay on the Bantustan airwaves. Love songs, songs of longing for home, songs about perseverance through troubled times, and songs that promoted traditional values over modern ways. But it was his hope that people would see though the lyrics to the symbolism of the beat:

Back then we couldn't sing militant songs, but we hoped that people would recognize [where] the rhythm [came from]. It was our way of saying "reggae is important, go and find the real deal" [Marley, Tosh, etc.] [this message] was lost on some people, but others, mostly young men like ourselves, we got it. It was very important in making us who we are today. (Interview with Colbert Mukwevho November $13^{\text {th }}$, 2009).

After the unbanning of the ANC in 1990, there was a gradual relaxation of official attitudes towards potentially subversive content in South African popular culture. ${ }^{4}$ In 1993 , Colbert signed a three album record deal with the CCP record company (EMI's South Africa group). With cash up front incentives, Colbert Mukwevho hit the big time. He moved from Venda to Johannesburg, into a penthouse flat in Yeoville's Harley Street, mingling with street poets, artisans, self-styled bohemians and associating with Yeoville's underbelly of gangsters who controlled the streets. Inspired by his 
turn of luck and new living arrangements, he changed his stage name to Harley and the Rasta Family, and set about recording his first professional studio album. CCP sent the master copies to Jamaica, and drums, bass and percussion were added by reggae legends Sly Dunbar and Robbie Shakespeare - both of whom had played with Bob Marley on many recordings. Two videos, for the two singles, were made on location in Mozambique and Mauritius, all expenses paid. Released in 1996, the album was a hit. The royalties were handsome, and Harley - as he was now known - went back into the studio to record a second album. But this time he wanted to do it differently. In his own words:

The first CCP album was nice, full of love songs and with a few covers that they forced on me. It was safe, very safe. I was proud of the quality. I man [sic] had waited many long years for this chance [but where was] my message, to the world? I wanted to say, fuck you, you kept us down now we are on top...but they [CCP] trapped me. I didn't want half of the songs they put on there. I just wrote them because I owed them, you know, for the house and the bills! I felt like this time, it was really my chance. (Interview with Colbert Mukwevho, November $16^{\text {th }} 2009$ ).

For the second studio album, Colbert had asked for and been granted more control over the overall production. He settled for a mix of Tshivenda and English tracks, with a distinctly militant feel. Entitled Why? it took just under a year to record, and was controversial in comparison to the previous album. It expressed political and religious views that attacked not only the previous regime, but the failures of the newly elected government. Songs such as "zwothe ndi Mahandana" (everything was for nothing), "God is Black", and "What We Need (Has Never Been Done)" left little to the imagination, and were distinctly reminiscent in style and substance of the Peter Tosh and 
Bob Marley albums of the late 1970s. Why? was released in 1998, but CCP did not invest in marketing or distribution and the returns were disappointing.

Colbert pushed ahead for the third album of his deal with the label. By mid 1999, he had recorded Doomsday which, as the title suggests, presented a pessimistic view of life in postapartheid South Africa. Particularly scathing of politicians and religious leaders, whom he referred to as 'lions in a sheepskin', Doomsday was musically accomplished, and lyrically aggressive. In the fourth track, "Set Us Free O Jah", Colbert breaks into a vocal adlib thus:

Yes you Mr. Preacher man, talk to me now! Why d' you take all this money, me no see you helping the poor and the needy around you... you are just like the government who has sat on the seat of Satan and sucks the blood of the sufferers every day!

Towards the end of 1999, Colbert presented Doomsday to the managers at CCP. The producers who had been allocated to work on the album pushed for its early release. They were to be sorely disappointed. Doomsday was shelved and the company never released a single copy. Whilst they accepted that musically the offerings were strong, company bosses felt that lyrically the songs went too far. Open political criticism of the government was, for them, unacceptable.

After over two years of protracted negotiations to force the release of his album, Colbert accepted defeat. He returned to Venda in 2002 with less money than he had left with in the early 1990s and, after a brief period of wealth and luxury, moved back into a room at the back of his parents' house in Thohoyandou. He had refused to re-record new lyrics over the same music, and CCP subsequently refused to relinquish the copyright for any of his work. The company informed him that the albums, along with the name 'Harley and the Rasta Family', were legal property of CCP records. Undeterred by their legal threats, however, Colbert released Doomsday and Why? under his own newly formed company. From the original master disks, he pressed hundreds of copies. The 
cover art was decidedly amateur, and marketing was through friends, family and local performances. Colbert's father owns a record bar, 'Survival Records', in the centre of Thohoyandou, which blasts out his music to passing shoppers and acts as an informal contact point for fans to gather and talk with the band if they happen to drop by. People bought the albums and profits were made.

After his decade-long flirtation with the formal music industry, Colbert Mukwevho found himself in the unusual position of having to illegally pirate his own music to recoup some financial returns for years of work. He borrowed a second-hand computer from a family friend, took out a loan for pirated software, found an old microphone and set up his own studio in a zinc shack behind his father's yard. The Burnin' Shak, as it was named, would become Colbert Mukwevho's recording studio from then until the present day, producing and releasing albums not only for Colbert and his new band - all of whom (except the author) are full brothers ('from the same father') - but for the many aspiring reggae musicians in the Venda region who sought to follow in his footsteps.

\section{'WE MUST SWEAT WHEN WE MAKE REGGAE':}

THE BURNIN' SHAK STUDIO.

Colbert Mukwevho's decision to open a recording studio was motivated by a desire for artistic freedom and financial gain. The informal music sector offered him the potential to control his own outputs and manage his own finances, although he has been more successful at the former than the latter. Moreover, he wanted to provide a platform for Venda reggae musicians to record, produce and release their material. With all this in mind, the Burnin' Shack opened its doors in 2003.

But, at a national level, reggae remains on the margins. The lack of a burgeoning national reggae scene is reflected in the categories of the annual SAMA awards, now in its sixteenth year. Whilst kwaito, gospel, Afrikaans, traditional/African, House and Jazz are well represented, reggae is excluded. Those reggae artists who have received national awards (Lucky Dube, Colbert 
Mukwevho, Tidal Waves) have done so in categories such as best single, best video or best regional artist. As a genre at the national level, it does not seem to make the cut.

Despite this lack of national recognition, reggae is hugely popular in Venda. The reasons for this can be traced back directly to the success of The Thrilling Artists, and the ways in which Colbert championed the genre in the mid 1980s. There is also a sense in which the Tshivenda language is phonetically suited to the genre. Tshivenda is spoken - and sung - with heavily accented, low tone, smoothly rounded phonemes. There are no clicks in the language, and Tshivenda lyrics seem to 'slide' over the one-drop reggae rhythm in a way that isiZulu or isiXhosa cannot. As a seSotho speaking DJ in Pretoria once insisted to me, 'it [TshiVenda] just feels right on reggae'. This is reflected in the shacks and stalls of hawkers and shop-owners in Thohoyandou, Sibasa, and in the predominantly Venda areas of Pretoria (Sunnyside) and Soweto (Tshiawelo), where the recordings of Venda reggae artists easily outnumber those of gospel, tshingondo or kwaito. In 2010, thirteen reggae $\operatorname{artists}^{5}$ released new albums, compared with eight gospel and six tshingondo. With only four exceptions, all of the reggae offerings were released through the Burin' Shak.

Depending on which genre they wish to record, aspiring musicians in Venda have a choice of studios and producers with whom they can work. Those who play tshingondo (a derivative of African rumba / soukous music, originating in the Congo) navigate towards the industrial estate of Shayandima to seek the services of Zozo, a Zimbabwean who has dominated the tshingondo scene for over ten years. Zozo is signed to Gallo/Warner, and as a result his albums are available in London, Paris and New York. His Shayandima studio offers an example of blurred boundaries between the formal and informal sectors; the studio is funded largely from profits he makes with Gallo/Warner, but it produces music for unsigned artists who are hoping to cross-over into record deals with a well established label. Between 2008-9, Zozo's domestic label released 6 albums, one of which received a South African Music Award (SAMA) for 'Best Venda Music' in 2009. Musicians who are interested in recording gospel are more likely to exploit networks of recording 
studios connected to local churches. Several gospel bands, such as Worship House, Rapson 'Mukhuwa' Rambuwani and Roxley 'Bishop' Masevhe, have set up recording studios associated with, and funded by, the churches they attend. Kwaito and hip-hop are catered for through networks based largely in and around the University of Venda, although a recent increase in Tshivenda hiphop and rap, associated with new artists such as Paperweight, Belafonte and Percy (Colbert's first born son) has seen a rival studio established in the village of Mulendane, and often travel to Gauteng to make recordings.

Those who wish to record reggae go to the Burnin' Shak. Colbert's younger brother, Mulalo, is in charge of recording and producing the artists. Mulalo is the bass player and sound engineer for Colbert's band, and an accomplished singer-songwriter in his own right. He charges between $\mathrm{R} 5,000$ and R8,000 rand (in 2010) to complete a 12-track album, with optional extras such as special effects, session guitar and live brass available at extra cost. Colbert purchased a comfortable chair for Mulalo to work in, but he insists on sitting on beer crates and old, broken plastic stools. 'It keeps me focussed', he claims, '... and we don't use a fan. We must sweat when we make reggae, like we are working in the fields...that's what gives Burnin' Shak that original feel...that's where reggae comes from...we are burning hot when we work in here, and the mix is sticky with sweat.' Indeed, during the day, the thin zinc roof that separates the studio from the sun serves to intensify the heat, turning it into an exceptionally hot working environment. Musicians, entourage, hangers-on, and local Rastafarians mingle daily, listening to the music, and relaxing in the yard. The smell of dagga mixes with aromas from the fire, sweat from the shak, and whatever happens to be cooking in the pot.

One of Mulalo's recent recordings was with Cornerstone; a young and critically acclaimed Venda acoustic reggae band. Cornerstone's experience exemplifies the economic uncertainties of recording in the informal sector. Their first album, Psalms, was recorded at the Burnin' Shak, and was nominated for a SAMA award in the category of 'Best Venda Music' in 2007. Whilst they did 
not actually win, the recognition of their talent - centred mostly on the hit single Tshifhire - attracted respectable media attention, and significant airplay on local radio stations. But despite this fame, Cornerstone was broke. They had borrowed money to press 200 copies of Psalms, all of which they had to sell in order to pay Mulalo for the time spent in the studio recording and producing the album. Mulalo had charged R8,000 for the album. The CDs, with cover-art, postage and packaging from Pretoria, cost R35 rand each, coming to a total of R7,000. Their bill was R15,000, and they had 200 CDs to sell, for R75 each, making exactly R15,000. But they struggled to sell them. R75 is expensive for a locally produced album - when American imports and professional South African music generally retail for just over R100. Locally produced music usually sells for between R40 and R60, but the special effects of the final mix, and the professional artwork, had pushed their price up. Nonetheless, they had little choice but to ask for R75, if they were to break even, and it was out of the question to ask people to pay any more. Mulalo had recorded the album largely on credit which he offered through his trust for the musicians, and he wanted his money.

Following their peers in the informal music industry, Cornerstone embarked on a low-budget, labour intensive marketing drive. They convinced friends and relatives to play the $\mathrm{CD}$ from their cars, park in shopping malls, beer halls and taxi ranks, selling the album to passersby. Taxi drivers were recruited to play the album and sell it to their customers. They borrowed speakers from the Burnin' Shak and performed small-scale miming shows in and around Thohoyandou, and at leisure resorts on weekends and during holidays (cf. Lamont 2010 in Kenya). Some local record shops bought stock from them, and others agreed to sell the CD from their premises without purchasing them upfront. This is a risky move for musicians, as it is never clear exactly how many CDs are sold. It is common for music shops to make pirate copies of an original, and sell the pirated copies for cheaper. When the musicians return to collect their money for CDs sold, the shop-owner insists that they have not been selling; leaving the musicians confused as to why they hear people playing their CDs around town. There have been some efforts recently to crack down on this style of 
pirating music, led by the gospel band Worship House, who pressed charges against several record shops in Venda. However they are unlikely to make any significant inroads against the extent to which music is pirated. The practice is commonplace, and the law against it is rarely enforced. After several months of marketing and selling Psalms, Cornerstone came out even, without making a cent from the album which had thrust them onto the local music scene.

Their SAMA nomination and the airplay they received, however, brought them to the attention of several local businessmen. Rendani, Cornerstone's song writer and self-appointed spokesman, began to receive phone calls from people interested in managing the band. Some of them were also interested in investing in them. As Rendani recalled:

I didn't trust any of them! They would call me and say 'Cornerstone are the next Colbert Mukwevho' and tell me that we had an international appeal because some of our songs I wrote in English, but I was thinking, how do they know?...they are not musicians...they just want to make money from us. I didn't tell them we had made nothing [from the first album]...I said to them, OK, we will go with the one who comes with the best deal for us - and the profits we will split 50-50. I was thinking to myself that we could not lose, you know, if we sell everything, and come out on zero again, then at least we didn't pay for time in the studio, so we should get something, not like with Psalms. My wife is pregnant, I need to get something, at least for the baby. (Interview with Cornerstone, February $18^{\text {th }}, 2010$ )

Cornerstone's second album, which they started recording in 2009 and completed in March 2010, was partially funded by their new manager, a successful young businessman I will call Mpho. Mpho accumulated significant wealth by successfully bidding for government tenders, although he dislikes the term tenderpreneur which, he claims, 'makes me sound like a crook'. The recoding process was 
haphazard; often being interrupted by Mulalo's other commitments as Colbert's bass player, sound engineer and producer. The second-hand computer on which the Burnin' Shak is completely dependent crashed several times and recordings were lost. Mulalo and the members of Cornerstone had become friends during the recording of the first album, and much of the cash advance for the album went into a drinking fund. Entire weekends were consumed by half-drunk jam sessions involving a string of musicians who were drafted in to play on the album (including the author, who was the session guitarist, backing vocalist, and contributed a song to the album). In the process, new songs were written and already recorded songs were altered, stalling the overall recording process. Mpho would call ahead to inform the band of his pending arrival. Panic would set in, and tracks would be hastily prepared for him to listen to. Eventually he lost patience and, having invested over R10,000 in the project, demanded that the album be ready by mid-March. The deadline was met, and Cornerstone's second album was released in May 2010.

During interviews, Mpho was cautious not to overstate his financial interest in the project, but his ultimate motivation for investing in Cornerstone was clear:

These guys needed a break. You have heard how talented they are, and they nearly got the [SAMA] award. I was talented too, and I only made it [became successful] after someone gave me a pat on the back and said, 'you are talented in business, here, take this [money] and make something of yourself. I paid him back after the first year, and look, now, things are going well for me. So I'm not saying this band is a business investment, but...well, if I can make my money back then that would be great. But the money is not in selling CDs, the money is in the [government] shows. That's where I want to take them, in that direction...as their manager I can do that, if they sing the right songs. (Interview, December $27^{\text {th }}, 2009$ ). 


\section{‘TENDERIZED PERFORMANCE’: MAKING MONEY FROM MAKING MUSIC}

As a successful businessman, Mpho's observations about the informal economy of musical production were astute. Cornerstone's experience of working hard to break even is - by and large the norm. For the artists of any genre in the 'second economy', writing and releasing CDs is an ineffective way of making a living. Widespread musical piracy and the expense of getting CDs manufactured on top of hiring a studio and a producer means that any financial gain from CD sales is channelled directly back into paying the debts accrued in making the album. Essentially, this is the same principle that governs the formal music industry, except that record companies, not individuals, front and recoup the cash. Likewise, in the informal economy, when a sponsor invests in an artist, he expects a return. By no means, however, is a return guaranteed.

Whilst the financial pickings are few, the potential to generate significant cultural capital is easier to harness. For a handful of musicians, who are not 'in it for the money', this is the only reward they seek. Artists such as 'Khatu', a successful social worker in Thohoyandou with a passion for reggae music, recorded his album at Burnin' Shak so that he could drive into beer halls or shopping complexes and hear people listening to his songs. I asked Khatu if he hoped to get money from his debut album. He responded that 'it would be great if I could make back what I spent $[R 5,000]$, but in [sic] the end of the day I just want to hear my music on car stereos and radio. We all grew up listening to Vhakwevho [Colbert and his family], so to do a reggae album in his studio was a dream come true...they played me on the radio last night, did you hear it?!' Khatu's quest for recognition was not entirely unsuccessful. One of his songs, 'Ni Ndelela Baadi' (You Disrespect Me So Much) receives regular airplay, and can be heard in beer halls throughout Venda. The fact that his fame may be short-lived is of little concern to him: 'I have my job, I get my salary, and anything else is a bonus'. 
As Khatu's experience demonstrates, songs can go from the studio to the radio in a matter of days, and every producer works hard to maintain good relationships with DJs in the local radio stations. Central to getting songs on air is the software and microphone used in the studio. Some programmes do not yield a sound of adequate quality, but software such as Newndo or - as used in the Burnin' Shak, Cue Base - can produce a sound that rivals professional studios for clarity, if the microphone is of a suitable standard. With the exception of live performances, however, a DJ is not legally allowed to play a track on the air unless it has been released as a single or album, registered or granted copyright. ${ }^{6}$ This is a straightforward procedure, involving a simple application form, but it can only be completed once the entire album is finished, as the same track cannot be copyrighted more than once. Nonetheless, sneak previews, in the form of demos or uncompleted mixes of the strongest tracks on an album, are regularly leaked to DJs, who accumulate their own kudos by being the first to play new music.

Cultural capital, gained through airplay, CD sales and the associated degrees of fame that come with such public exposure, is not easily converted into hard cash, although various schemes have been devised with precisely this in mind. Many investors - such as Cornerstone's manager and music promoters have attempted to organize concerts in Venda, Pretoria and Soweto, mostly in the form of a 'battle of the bands' in which several acts take to the stage. With very few exceptions, these have been abject failures, often ending in violence. A litany of procedural obstacles faces anyone who wants to organize and make money from such a show. Permission must be granted from a municipality, a big sound system must be sourced with a good sound engineer to work it, security must be in place, a venue must be organized, funding must be sourced, publicity must be strong and, most importantly, the promoter must be able to guarantee that the advertised acts will indeed perform.

It has become common in recent years for posters to appear in and around Thohoyandou, advertising a forthcoming show with a list of artists. A recent example, in November 2009, 
confidently asserted that Colbert Mukwevho would be performing with Khakhathi and Friends, another local reggae act. Neither Colbert nor Khakhathi, however, had been asked to perform at the show. The evening of the supposed performance arrived, and people started to pay their R50 entry fee. The hours passed, the crowd grew, and eventually the organizers phoned Colbert. They informed him of the crowd waiting for his arrival, and suggested that he should not disappoint so many fans who had paid to see him perform. Colbert sent a group of friends to investigate the situation at the venue. Indeed, there was a reasonable crowd, but the security was nonexistent and the sound system was far too small to accommodate his band. He didn't turn up, and the crowd started throwing bottles on the stage, eventually fighting among themselves in drunken frustration. The promoters ran off with a tidy profit, and left Colbert with a public relations nightmare that required radio and newspaper interviews to smooth over. On other occasions, promoters have attempted similar stunts, but after depositing cash into Colbert's account at the last minute (of which he was notified via an automatic text message from the bank), he grudgingly performed.

Entrepreneurs seeking to make money are in a difficult situation when it comes to organizing privately funded concerts in Venda. If the sound system is too small, artists may refuse to perform. But the low cost of hiring a small sound allows for affordable ticket prices (R30-50), making it more likely that people will attend. They are often disappointed when the bands decline to perform on account of the small sound. If, on the other hand, the sound system is big (meaning they have paid a significant sum to hire it from Gauteng) then the ticket price will be higher (between R70-100), and people will be less likely to attend. After paying for his girlfriend's ticket, stocking up the cooler box and organizing food and transport, an average young man in Venda can expect to pay upwards of R500 for the night. Not many can afford that. Moreover, with a big sound system, fans can hear the music from outside the venue, and so congregate in the car park, drink from their cooler boxes, and enjoy a free gig. The musicians are more likely to perform, but less likely to get paid because of the poor ticket sales. Either way, promoters, performers and the paying public have grown weary 
and suspicious of privately funded shows. They are, quite simply, not worth the trouble for everyone involved.

But there are other reasons for the slump in privately funded shows. The public knows that if they wait for a month or so, the artists will perform at a government show. These occur frequently and are free for all to attend. Over and above South Africa's 15 public holidays, the government hosts a range of events celebrating and commemorating international and national events. Harley and the Rasta Family, for example, were joined by various other acts from Venda and Gauteng recently in the border town of Musina to celebrate International Toilet Day. In a bizarrely appropriate twist, the backdrop to the stage was an artistic impression of a huge toilet cistern, and the stage itself was in the shape of a large toilet seat. The bands performed, and the dignitaries delivered their speeches, in a setting that was certainly suited to the theme of the occasion which, in all seriousness, promoted toilet hygiene in an area where deadly outbreaks of cholera have recently occurred amongst groups of Zimbabwean refugees.

Regardless of the events which they celebrate or the causes they propagate, government shows have a distinct and very formulaic order of proceedings. They start at 10am, by which time bus loads of people will have been transported into the venue, which is usually a stadium or sports ground. Transport may be provided by the municipalities, or put out to tender separately from the provision of food, portable toilets and entertainment, all of which generally have their own separate budgets taken from the central pot of cash. Security is provided by the police, or if a senior government official if present, by the South African Defence Force. From around 11am, the dignitaries (politicians of various importance, members of groups representing the issues of the day, traditional and religious leaders) begin to arrive, taking their seats on a shaded podium on the stage. The master of ceremonies opens the event by asking a pastor to say a prayer, after which each dignitary takes to the podium and delivers a speech which, theoretically, addresses matters pertinent to the gathering. By around $1 \mathrm{pm}$, with the completion of the speeches, the dignitaries retire to a 
nearby tent, erected especially for their hospitality and protected by a significant police presence. At the same time, a meal of pap (maize porridge), meat and a soft drink is provided for the crowd, which can number well into the thousands. As they wait for their free meal, the entertainment sets up on stage. A quick tune-up is followed by an ever quicker sound-check, and the first act begins their set. Each set should last between forty-five minutes and an hour, and every show has three or four acts lined up to amuse to masses as they digest their meals and enjoy a free day out. The busses depart around 5pm, at which point the venue empties rapidly, leaving behind those who live nearby to listen to the last act, before the electricity is cut off, and police remove everyone, by 6'o'clock in the evening.

Depending on the budget available, the organizers will aim for a mix of locally and Gauteng based acts. The Gauteng bands, signed to major labels, command a much higher price than the local musicians, who can expect payment in the range of $\mathrm{R} 35,000$ - R60,000 depending the relative popularity of the act, and on how well negotiations between the artist and the organizers have went. Corruption in these protracted discussions has become convention. It is common for a musician to be offered a contract of, for example, R40,000, on the condition that he agrees to give a proportion of this payment back to the person making the decisions. The kickback is generally in the region of $10 \%$, and is always demanded cash in hand. Artists generally receive $50 \%$ of their payment before the show, and the remainder after the performance. This serves to ensure that they will actually perform, and to cover transport and food, etc., but also makes it convenient for the outstanding sum to be delayed if the kickback is not forthcoming.

The tenderpreneurs who win the contracts to organize the entertainment at such shows often have a background in musical promotion. They mostly adopt a 'hands on' approach to providing their service, whilst other tender winners completely outsource their duties to smaller companies. Whether they take a 'hands-on' approach or out-source, of course, the successful bidder creams off a substantial, but unspecified, amount from his total budged allowance. Often, the entertainment 
organizers will have had working relationships with musicians for many years, as I discussed above, through abortive attempts at privately funded concerts. Whilst such private concerts are fraught with financial and organizational pitfalls, government shows are relatively easy to deliver. With separate tenders for transport, ablutions, catering and entertainment, their duties are clearly outlined, security is provided by the state, and their money is given, in abundance, up front. With other tender winners taking care of getting people to and from the venue, and without the concern that money will be lost through low attendance, the provision of sound and the procurement of a few acts is easy money for old rope.

But whilst the successful bidder for the entertainment tender may have known the musicians for some time, their relationship may not necessarily be a harmonious one. Music promoters have long endured an acrimonious association with musicians; both parties are symbiotically dependent on each other, and both attempt to yield increasing influence over each other in a bid for mutual survival. Before this relatively recent government coup on music concerts, the musicians held the upper hand in this relationship. It was they who could choose to perform or not, and they could choose what to perform, setting the terms of their own engagement with the promoters based largely on payment and the provision of adequate sound. The tables have now turned. Musicians in the informal sector have significantly lost power in their ability to negotiate with promoters, largely because of the huge sums of money the government allocates them to pay the acts, and to rent huge sound systems for a guaranteed capacity crowd.

Musicians have been disempowered by the financial necessity to perform at government shows in order to make money from their music. It is the promoter that decides who will perform, and if they make the correct decisions - and the show gets the approval of its explicitly politically motivated sponsors - then he increases the chances of being awarded another tender. In this way, the successful bidders for entertainment tenders at government shows are not necessarily politically motivated, although they may well be card carrying members of the ruling party, and will have 
become politically connected during the course of sealing their deals. Rather, they are astute business people, 'entertainment tenderpreneurs', who know their audience well and tailor the service they provide to tickle the sensibilities of those who allocate the tenders.

All this contributes to the situation whereby the musicians must resign themselves to a performance that is either apolitical or, preferably for the organizers, pro-government. This is no problem for many of the acts who are regulars at government shows. Rapson 'Mukhuwa' Rambuwani regularly takes to the stage donning an ANC baseball cap. Roxley 'Bishop' Masevhe, has recorded albums thanking God for the government and the traditional leaders who support it. Many of the Gauteng acts who travel north to Limpopo for the shows are well known supporters of the ANC: Arthur Mafokate, Solly Moholo and Kanyi Mbau, to name but a few. Reggae, however, is famously critical of the political system in which it finds itself. Reggae musicians, at least the ones with whom I work and perform in Venda, often articulate a sense of obligation to speak out against injustice and inequality, and many (although not all) had hoped that, with the fall of apartheid, their time had come to do just that.

But singing the truth to power has undesirable consequences for musicians in post-apartheid South Africa. In May 2005, at a government show in Polokwane celebrating International Workers Day, Venda reggae artist Khakhathi Tshisikule took to the stage in his trademark trench coat (dzhazi). Khakhathi is not known for his vocal ability, but he is a charismatic performer, and interacts with the crowd in a way that few Venda artists can emulate. His opening songs had the crowd dancing to his beat, and before he went into the third track, Khakhati announced that he was about to perform a new song. Concerned that the crowd might stop dancing as they were unfamiliar with the song, he cut the band completely and started to teach the audience the words. "Vhamunicipala a vha shumi, humbulani zwa kale, dzi roboto dzo shuma Thohoyandou, vhathu vhasongo hangwa uri mushumo u a pfa hani, li doda duvha!" (The municipality is not working, remember the days when traffic lights in Thohoyandou worked, people, don't forget the way that 
employment feels, because our day is yet to come!). The band kicked in, and the song was under way. Halfway through the second verse, the power was disconnected.

From that day on, Khakhathi Tshisikule has been sidelined from every government show. He became persona non grata overnight. His music was no longer played on radio, and various smears appeared against him in the local media. Never one to shy from publicity, Khakhathi approached the media himself, and protested that he had been 'banned for telling the truth'. He struggled to find a studio to record his subsequent album, but eventually released a low budget $\mathrm{CD}$ under the name Madzhazi (in reference to his trench coat) on which he escalated his critique of service delivery and corruption in the municipality. Khakhathi had been banished from the government show circuit, and reggae musicians in Venda looked on, learning from his mistakes. Although he remains unrepentant, he no longer makes money from his music. Instead, he joined a small independent radio station in Louis Trichardt, Makhado FM, hosting their reggae hour on a Saturday morning and is supported financially, perhaps ironically, by his wife who has a successful business bidding for catering tenders from the Thulamela municipality.

After the Polokwane incident, the way in which reggae musicians approached government shows changed profoundly. Serious thought was put into the suitability of songs, and anything that was considered risky was struck from the set list. Other musicians had previously performed songs of a critical nature, but none had been so explicit in their critique as Khakhathi, who, without metaphor or obfuscation, had openly criticized a structure of government. A culture of selfcensorship was immediately adopted. Colbert Mukwevho, who is still a regular on the government circuit, took no chances. With over ten people directly dependent on him for their daily survival, he was weary of biting the hand that feeds them. Several songs in his line up were potentially insulting to the government dignitaries who were listening to the entertainment whilst enjoying their tented hospitality at the shows. Songs such as Nganiwapo, Doomsday and What We Need (Has Never Been Done) were replaced by ballads such as Nne na Inwe, No Woman No Cry, and other 'safe' 
Bob Marley covers such as Jammin' and Trenchtown Rock. For Colbert, this was like a return to the apartheid era:

Look at all these guys who sing God bless the ANC, and check the cars they drive. Now look at people who sing the truth, they have been made into lepers. It's just like apartheid, we are forced to say everything is alright so we can get some food on the table. But it's not like we have lost, or sold out to them. The [Burnin] Shak still releases albums that speak [honestly], we just do it in a hidden way, so if it's not so obvious then they don't mind. So we can release it, but it's not safe to perform...we need the money...yeah, money is the devil! (Interview with Colbert Mukwevho, Feburary $1^{\text {st }}$, 2010.)

As Colbert explains in the quote above, reggae musicians still record and release albums with what could be considered critical content. But they censor themselves in a way that renders the critique more a consequence of reggae music than of the artists' discontent with the current political dispensation. Through linguistic obfuscation, they lend political correctness to their social and political critique. An example of this is the subtlety employed in Colbert's recent album, entitled 'Mmbwa I do la Mmbwa' (Dog Eat Dog). In the title track, he invokes deep linguistic metaphor to suggest that human nature has led South Africa, and the world as a whole, into a state of deranged confusion at the gates of Armageddon. The metaphor can have many readings, one of which is that politicians are so consumed with greed and self enrichment that they will literally eat themselves. Of course this is not the only interpretation, another could be that God has made us all greedy, and we are all, as a human race, destined to self-destruction. As Colbert explained: "it helps these days to hide what you are trying to say...but we have lots of practice, I started when I was ten in my 
father's band...it's in the blood for us to hide the truth'. In the blood it may be, but on the set list for live performance, it is not.

\section{CONCLUSION}

The Burnin' Shak was established as an informal recording studio in the hope of achieving artistic freedom and economic gain. The ethnography in this paper demonstrates that, in pursuit of the latter, the former is compromised. It would appear that in order to make money from making music, artists in South Africa's informal economy have little choice but to sanitize their live performances. Although it is perhaps an unintended consequence of the process by which government shows are funded, bidding for tenders is inseparable from the erosion of artistic integrity. Perhaps ironically, for the musicians involved, this is reminiscent of apartheid era politics in which a culture of selfcensorship prevailed amongst purveyors of popular culture. During both of these recent periods in South African history, musicians and producers have been encouraged to mind what they say. None wish to be seen as opposing the ruling party, lest they be expelled from the list of potentially paid performers.

The ethnography here has also highlighted salient trends in the economic organisation of the informal music industry. It is clear that the boundaries between 'first' and 'second' economies are blurred and shifting, and the desire to move from the latter to the former is rarely achieved. Indeed, as we saw with Colbert Mukwevho, musicians are as likely to move from the first to the second realms of musical production as they are to 'progress' into the formality of record deals with major labels. Moreover, circulation of capital between the two makes any distinction between formal and informal economic processes difficult to maintain, although the pragmatics of making music in the formal and informal sectors are quite distinct. Central to the practice of recording and production in the informal sector is the role of trust: Trust has emerged here as the 'glue' that holds the cycles of 
credit and debit together, and through trust, the informal economy of music making produces albums for public consumption.

However once the album leaves the studio, networks of trust break down almost entirely, and music piracy has emerged as an ambiguous player in this story. On the one hand, it complicates CD sales and reduces the direct revenue that musicians make from selling albums - much of which is funnelled back into paying debts incurred during the recording process. And yet on the other hand by selling cheap copies of their music, those who pirate originals are increasing artists' popularity, and thus making it more likely that they will earn significant money through performances. Because of his critical social commentary, Colbert Mukwevho found himself in the unusual position of having to make illegal copies of his own music, against the will of his former record label but with little option to make ends meet. Having been sidelined by the formal recording industry, Colbert's attempts - like those of others in the informal sector - at voicing direct social and political critique through the 'second economy' of musical production have met with very limited success. Metaphor and obfuscation are the order of the day, and musicians often structure their productions to suit the proclivities of the ruling party. If they don't, then they have to find another job. They have had to adjust to the fact that their musical autonomy has been undermined by the process of tender allocation, upon which they are dependant for the conversion of cultural capital into cash.

\section{REFERENCES}

Baines, G. (2006) 'Racist Hate Speech in South Africa's Fragile Democracy: the case of Ngema's 'AmaNdiya', in Drewett, M and Cloonon, M. (eds.) Popular Music and Censorship in Africa. London: Ashgate. 
Coplan, D. (1979) 'The African Musician and the Development of the Johannesburg Entertainment Industry, 1900-1960.’ Journal of Southern African Studies, Vol. 5, No.2.

(1985) In Township Tonight! South Africa's black city music and theatre. New York and London: Longman; Johannesburg: Ravan.

(2005) 'God Rock Africa: thoughts on politics in popular black performance in South Africa.' African Studies, 64, 1.

Drewett, M and Cloonon, M. (eds.) (2006) Popular Music and Censorship in Africa. London: Ashgate.

Erlmann, V. (1996) Nightsong. performance, power and practice in South Africa Chicago and London: University of Chicago Press.

(1991) African Stars: studies in black South African performance. Chicago: University of Chicago Press.

Lamont, M. (2010) 'Lip-Synch Gospel: Christian music and the ethnopoetics of identity in Kenya.' Africa. 80 (3):

McNeill, F.G. (forthcoming) 'Rural Reggae: the politics of performance in the former Venda Bantustan',. South African Historical Journal 
Meintjes, L. (2003) Sound of Africa: making music Zulu in a South African studio. Durham and London: Duke University Press.

\begin{abstract}
This paper presents an ethnographic analysis of the popular economy of informal musical production in the Venda region of South Africa. It focuses on the activities surrounding the Burnin' Shak Studio; a recording house that specializes in reggae music. Reliant on second-hand computers, pirated software, borrowed instruments, networks of trust and cycles of debt, musicians and producers in the Burnin' Shak occupy a distinctly peripheral position in South Africa's music industry. Unlike artists in the formal sphere of musical production, who sign deals with specific record labels, musicians in the informal sector seek out sponsors - usually young local businessmen - to fund their recordings with local producers. Marketing and distribution is the sole responsibility of the artist and their sponsor, who often develop a 'patron/client' relationship. And yet whilst their artistic entrepreneurial activity often earns them significant airplay on local radio stations, and associated cultural capital, the financial benefits are slim. In order to convert their cultural capital into cash, musicians in the informal sector must compete in the market for performances at government-sponsored shows. These shows are well funded by lucrative tenders, but they present musicians with a double-edged sword. To secure a contract with tender holders - or to entertain hopes of regular paid performances - musicians must ensure that their performances do not express critical political sentiment. As purveyors of a genre renowned for its critical social commentary, reggae musicians are particularly affected by this expectation of self-censorship. Informal musical production in the post-apartheid era thus affords musicians little artistic freedom. Rather, whilst the products of this culture industry may appear to be part of a 'secondary' economy, removed from the spheres of formalized production and control, they are in fact regulated and standardized through the process of tender allocation.
\end{abstract}


Fraser G. McNeill is a senior lecturer in the Department of Anthropology and Archaeology at the University of Pretoria in South Africa. He has been conducting ethnographic research in the Venda region of South Africa for over 10 years, and is the author of AIDS, Politics and Music in South Africa (Cambridge University Press, 2011).

${ }^{1}$ See also, for example, Coplan 1979, 2005; Drewett and Cloonen 2006.

${ }^{2}$ I have been the lead guitarist in Colbert Mukwevho's band since 2002. This was originally a hobby, only becoming a matter of ethnographic enquiry in the last few years. Much of my fieldwork for this paper was spend 'hanging out' in local studios, where I also work as a session musician and producer for reggae bands. This has afforded me privileged access to the inner workings of the informal music industry as I am, in effect, a part of it. The methodological approach for this analysis thus falls squarely within the realm of participant observation.

${ }^{3}$ Radio Freedom was the ANC radio station broadcast mainly from Zambia and controlled by 'comrades' in exile.

${ }^{4}$ It is important to stress here that not all musicians wilfully resisted the political situation at the time. Many remained apolitical, and Colbert Mukwevho is himself is ambiguous and often contradictory in his recollections of the role that music played in 'the struggle'. See McNeill (Forthcoming); Coplan (2005).

${ }^{5}$ The artists in question here are Shufflas, Khatu, Khakhati and Friends, Ntshenge and the Jah Live, Alu and the Roots Nation, Jahman Tshiganja, Colbert Mukwevho, The Mukwevho Sisters, Cornerstone, The Burning Doctor, The Vision Sound, Soul 'Burning Soul' Nephawe and Just-Ice. ${ }^{6}$ Several DJs I have spoken to dispute this, claiming that modern production techniques, and the extent of piracy, make the law completely unenforceable. They cite DJ remixes of house music, and 
other digital media which are arguably 'original', as an example of how the copyright of contemporary musical productions is impossible. (The same samples appear in countless house tracks, and the 'original' composers have long given up fighting for royalties). 